\title{
A Fuzzy Approach for In-Car Sound Quality Prediction
}

\author{
Judit Lukács \\ Óbuda University, Donát Bánki Faculty of Mechanical and Safety Engineering, \\ Népszínház u. 8, H-1081 Budapest, Hungary; lukacs.judit@bgk.uni-obuda.hu
}

\begin{abstract}
Numerous methods exist to characterize product quality. Nowadays, in the case of road vehicles, one of the most important issues is the acoustic comfort of the interior. However, the detection of the traffic environment is a further key question. In the case of minor vehicle collisions, the perceptibility is to analyze. Within the framework of the current study, the results of airborne noise measurements are presented. Experimental data were used to design predictive fuzzy models to estimate cabin noise level, which is in connection with the audibility of outer sourcing sounds. Two concepts of inference systems were investigated by examining accuracy, conformity and 0 residuals: Mamdani and Sugeno type ones. It was finally concluded that for estimating interior noise, Sugeno type fuzzy model is the better choice, as the accuracy and conformity are higher. In addition, the range of residuals is a magnitude lower: Mamdani type FIS provided -2.30 $2.30 \mathrm{~dB}(-$ $3.84 \sim 3.30 \%$ ), Sugeno type one resulted $-0.40 \sim 0.20 d B$ (-0.57 0.33\%). Furthermore, the residuals follow a Gaussian distribution, in the case of the Sugeno predictive fuzzy model.
\end{abstract}

Keywords: minor vehicle collisions; accompanying sound phenomenon; acoustic perception; airborne sound; vehicle interior noise; sound quality; pink noise; noise prediction; Mamdani-type FIS; Sugeno-type FIS

\section{Introduction}

In recent decades, issues concerning noise and vibration control of vehicles have gained significantly more attention. Based on consumers' expectations, an important part of travel comfort belongs to the acoustic well-being of the driver and the passengers as well. As a result, the reduction of vehicle noise level is a primary question regarding the interior and even noise emission. On the one hand, noise insulation of the cabin is to improve, which means diminishing the audibility of unwanted sound effects from external sources: road, traffic, etc. Furthermore, environmental issues also have to be taken into account. However, road safety concerns are not to be neglected. The perception of the traffic environment (other cars, vehicles using distinctive signs, pedestrians, etc.) is among the most important criteria. So, noise control in automotive sense is a complicated question nowadays. 
Regarding traffic and other concerning issues, it can be stated that in the past decades our habits have changed remarkably. Since the urban population is increasing, the amount of vehicles circulating on the roads and in suburban areas is raised. Additionally, the majority of youngsters have delays in obtaining a driving license. As a result, they are less experienced drivers on overcrowded traffic environment [1].

Human factor is the most controversial parameter in traffic safety questions, even in the detection of the road environment. Kosztolányi-Iván et al. [2] revealed that some road types are for road users easier to recognize than some other types. That issue strongly corresponds to speed choice. It was stated that the ideal solution for road characteristics is reached when having 5-6 categories. Additionally, Fazekas et al. [3] found that environmental perception capabilities - since it is an expressly human feature - can be supported by biologically inspired systems. Their method to detect road environment, the so-called RoED (Road Environment Detection) system, was able to distinguish urban road types based on traffic signs and crossroad data. For that propose, a feed-forward artificial neural network trained in a supervised manner was generated.

Several further disagreements were stated in terms of the effect of passengers on driver's behavior and performance. Since peer pressure is a critical question in mind, a significant connection can be found with the severity and outcome of traffic accidents.

One way to investigate the effect of passengers is to carry out studies on policereported crash data.

Orsi et al. [4] operated with the driver's injury in the accident to grade the impact of the company traveling in the vehicle. Incidents that occurred in Pavia, Italy, in 2004-2005 were used in the investigations. It was revealed that drivers aged under 25 years are more likely to get injured in case of the presence of passengers than those who drove alone. However, older chauffeurs have a higher probability of taking part in single-vehicle crashes in case of the absence of company.

Nevertheless, the protective effect of passengers was revealed by Vollrath et al. [5]. Statistical analysis was fulfilled on data of vehicle collisions in Germany, 1984-1997. However, only multi-vehicle crashes were studied. It was found that passengers reduce the risk of an incident by giving a hand to the driver when critical moments occur. Also, drivers are more careful by keeping distance and avoiding to speed.

Further studies [6] [7] revealed similar effects. Being accompanied by passengers resulted in a higher likelihood of seatbelt use. In addition, crash potential and committing traffic violations are decreased as the number of passengers increases.

Maasalo et al. [8] investigated a specific stratum of the driver population: those who had children passengers. Crash data from the USA between 1996-2015 were used in the analysis. Those incidents were chosen that occurred in public traffic ways, passenger was in the vehicle, and at least one person died within 30 days of 
the incident. It was revealed that female drivers are more likely to take part in fatal crashes. Additionally, having children passengers caused a higher level of distraction, but less amount of risk-taking behaviors were typical.

McEvoy et al. [9] compared the effect of mobile use and passenger carriage regarding the risk of a crash. The input data for statistical analysis were gained from incidents that occurred in Perth, Western Australia, in 2003-2004. Multiple logistic regression model was generated. It was stated that the use of mobile phone within 5 minutes before the accident, provided four times higher probability of taking part in a collision. The enhanced number of passengers resulted in a higher crash risk as well, but to a lower extent. Furthermore, the age and number of passengers and the age and the sex of the driver were examined. It was revealed that drivers tend to interact with the company traveling in the vehicle. The increased number of passengers also results in a higher risk of hospital attendance of the driver.

Another way to study circumstances that strongly affect driving performance is by carrying out driving tasks in a driving simulator. The concept was applied by Chan et al. [10], who said that more focus is needed in case of the presence of a company in the vehicle. Their investigations were based on results provided by examinations performed in a driving simulator.

Driving habits of young Korean drivers were analyzed by Chung et al. [11] by the help of a driving simulator. The people who took part in the study were divided into three groups: the first part consisted of automobilists who drove alone, the members of the second one were driving with a passive and the third with an active passenger who was giving useful driving tips. It was revealed that the third group was more likely to slow down; however, in terms of traveling speed, no significant difference was found between the first and the second group.

Minor vehicle collisions belong to a special section of road accidents, where the impact speed is $v_{i}=1 \sim 5 \mathrm{~km} / \mathrm{h}$, the key question is to investigate the perceptibility of the incident [12]. However, the concept is not clearly defined as several problems are to face.

In contrast to accidents occurred with higher velocity, several problems are to handle from judicial, medical, and technical points of view as well. Regarding engineering concerns, the accompanying sound phenomenon of minor collisions is in most cases at the threshold of human hearing. Additionally, the detection is worsened by operating auxiliary equipment in the interior (e.g. HVAC and audio systems, etc.) and by the company as well. Furthermore, the magnitude of the impact energy is much lower, thereby only slight optic surface damages (scratches) are resulted after the incident. The most or the whole part of that energy amount is absorbed due to the design and materials of modern bumper systems. The requirements laid down in the Regulation of bumpers include the expectation to absorb impact energy by elastic deformation until a determined impact velocity: $v_{i} \leq 4 \mathrm{~km} / \mathrm{h}\left(v_{i} \leq 8 \mathrm{~km} / \mathrm{h}\right.$ in the USA) [13]. 
What is more, several further aspects have to be taken into account when designing automotive bumpers. Liu C. H. et al. [14] presented a new concept to analyze bumper covers. A numerical model based on finite element analysis was constructed to investigate the stiffness of the bumper covers under a variety of loading conditions with the requirement to minimize bumper deflection. A new concept of design was presented that consists of increasing the thickness only at the side of the cover by avoiding unnecessary additional weight.

In addition, Scott et al. [15] developed a numerical analytical model based on previously occurred crashes for bumper-to-bumper minor collisions to carry out parametric studies and estimate the severity of the incidents. That provided input data for simulation and the ability to depict vehicle dynamics in the accident.

Item, further difficulties can be faced at the temporal analysis of the incidents. Since the impact energy is quite low, the phase of vehicular separation after the crash is mostly missing, which makes the perception and realization more complicated.

In analytical aspects, based on Schneider's concept, the detection is to investigate in three different fields with the following features:

\section{Visibility}

- $\quad$ Means perception via seeing

- Characterized by the orientation of the driver's gaze

- $\quad$ For most minor collisions, poor visibility happens

\section{Audibility}

- Also known as acoustic detectability

- Influenced by plenty of parameters: acoustic insulation of the cabin, background noises from inner and outer sources, etc.

\section{Tactile and kinesthetic appreciability}

- $\quad$ Related to the sense of balance

- Stiffness of the vehicle body is not homogeneous

- Detectability is connected to the location of the contact [16]

Nowadays, noise, vibration, and harshness (NVH) are gaining importance in the case of vehicles. On the one hand, noise pollution is one of the environmental problems that mostly affect the population. Additionally, in particular, vehicle interior noise is a key parameter judged from customer side, since that issue strongly influences the comfort of the passengers. As a result, acoustic measurements are widely used in all fields of transportation. 
In the past few years, attention drawn to issues concerning noise and vibration is increased not only in automotive but in military vehicle industry. Liu Z. S. et al. [17] presented analytical model and methodology to estimate the interior noise of tracked vehicles (for civil engineering and military applications as well). Results of finite element and boundary element models were compared with measurement data. The aim was to generate a tool for further noise reduction for that type of vehicle.

Bera and Pokorádi [18] [19] studied aircraft noise in several examinations, regarding its measurements and protection. Since equivalent continuous sound pressure is strongly connected to environmental changes, that parameter was used to investigate the influence of noise. Furthermore, a Monte-Carlo Simulationbased method was presented in order to examine the noise load of helicopter aerobatics from energetic point of view.

The effect of aircraft interior noise on human performance was analyzed as well. Lindvall and Västfjäll [20] investigated the effect of sound recorded in a cockpit. Ivošević et al. [21] carried out quite similar examinations.

Traffic noise consists of many sorts of individual noise sources. In the case of road vehicles at micro-level, these components are engine, exhaust, transmission, tire, road noise, aerodynamics, and body. To calculate noise emission of road traffic, traffic noise prediction models are utilized, the vast majority of which operate with equivalent continuous sound pressure level as output as it is proper for objective evaluation of noise levels.

Singh D. et al. [22] applied four different methods to evaluate hourly traffic noise in Patiala, India: a generalized linear model and three types of soft computing methods: decision trees, random forests, and artificial neural network. 10-fold cross-validation was performed, and the prediction results were compared. It was revealed that the random forests technique provided the highest accuracy and stability. However, the extension of the number of variables would improve the models.

Concerning sound quality of road vehicles, the aim is to improve acoustic comfort. A further key issue is the quality of noise. Evaluation methods can characterize the interior noise level of vehicles. However, the sound perception of humans is influenced by personal factors as well [23].

Several experimental techniques exist to investigate noise and vibration in commercial vehicles. The main sources are the following based on Panza:

For Noise:

- Engine

- Road noise

- Aerodynamic noise

- Secondary noise sources: brakes, electrical, mechanical accessories, etc. 
For Vibration:

- Reciprocating/Rotational masses - pistons, connecting rods, shafts etc.

- Transmission

- Road-tire interactions

- Vehicle body [24].

As it was previously mentioned, the acoustic comfort of passenger cars is a vital issue nowadays. However, a further important question is the perception of product quality via sound. That concern is strongly connected to consumers. Pietila et al. [25] say that it is difficult to meet these expectations. Relative evaluations have to be carried out as there is a wide variety of products in the automotive industry. For instance, excursive expectations are set based on previous experiences (e.g., the engine noise of a Harley Davidson). For that purpose, intelligent methods and soft computing techniques are highly welcomed in evaluations.

Chen et al. [26] carried out acoustic measurements to investigate several sound quality metrics of the interior: sound pressure level, roughness, sharpness, and loudness. Based on experimental data, an artificial neural network was built to predict these parameters. Having compared measured and calculated values, the intelligent system was found to be proper to estimate automotive sound quality. In addition, as a part of a further study [27], the aim was to reveal the relationship between objective parameters and subjective evaluations. Interior sounds of 8 sample vehicles at different working conditions were recorded to fulfill subjective examinations. The results of traditional correlation analysis were compared to those of Grey Relational Analysis. It was concluded that based on GRA results, the interior sound quality could be enhanced.

Convolutional neural networks are also used for traffic sign recognition, especially in the case of autonomous vehicles [28].

Booming and rumbling noises play an important role when characterizing interior sound quality. Lee S. K. et al. [29] applied a multi-layer feed-forward artificial neural network trained with back-propagation algorithm for development. Interior sounds were registered and subjectively evaluated by 21 persons. Results were tested on mass-produced passenger cars with high accuracy.

Parizet et al. [30] investigated the perception of noise and vibration of commercial vehicles equipped with 3 and 4 cylinder diesel engines running at idle. Their aim was to compare and evaluate signals impacting acoustic comfort in the interior.

In fact, the interior sound quality is strongly influenced by the noises sourcing from the outer environment. However, the effect of these disturbances is weakened by the noise insulation capacity of the cabin. On the other hand, the relationship between the internal noise sources and acoustic perceptibility is more intensive. 
Angelescu et al. [31] investigated the effect of heating, ventilation, and airconditioning system on vehicle interior noise levels. In their examinations, different types of ventilation grids were studied. It was stated that the cabin noise mostly consists of the disturbing noise generated by the operation of the fresh air fan. Furthermore, among the investigated grid types, the initial one was found to be the less disturbing one.

Preliminary studies were carried out as well by investigating the perceptibility of pure sine tones. The aim was to determine those parameters that are strongly connected to the lowest level of detection. With the help of Design of Experiment and statistical techniques, significance test was fulfilled. It was revealed that it is the operation of the internal combustion engine, and further auxiliaries (especially the fresh air fan) are the most influential factors [32]. Additionally, based on airborne sound measurements, a prediction model was constructed with the help of response surface methodology to estimate cabin noise at multiple working conditions. The generated model provided adequate accuracy; the equivalent continuous sound pressure level was calculated within $\pm 3 \%$. The conformity of the model was investigated by the help of residuals and was verified by confirmation measurements [33].

In this paper, the results of airborne sound measurements are presented. In the experimental setup, multiple working conditions are investigated. Experimental data are used to build up two types of fuzzy inference systems: Mamdani and Sugeno-type ones. The aim of the constructed MISO models is to predict cabin noise levels with higher accuracy. Based on the results calculated by the different FIS methods, the optimal technique is chosen. The structure of the article is the following: the literature review is followed by the section of applied methods, where the concept of measurements and evaluation is presented. Thereafter, investigations are introduced. This part consists of experimental results, model construction and comparison of prediction concepts. Finally, conclusions are drawn.

\section{Methods}

\subsection{Measuring Method}

Investigations were performed on a SKODA FABIA COMBI B-segment estate car. The technical data of the sample vehicle are shown in Table 1.

Acoustic measurements were carried out with a Hohner Stereo 50 portable double speaker sound system and a Svantek 959 Sound\&Vibration Analyzer. 
Table 1

Technical data of SV

\begin{tabular}{|c|c|}
\hline Make & SKODA \\
\hline Model & FABIA \\
\hline Year & 2004 \\
\hline Displacement & $1198 \mathrm{~cm}^{3}$ \\
\hline Number of cylinders (valves) & 3 cyl. $(12 \mathrm{~V})$ \\
\hline Power & $47 \mathrm{~kW}(5400 \mathrm{rpm})$ \\
\hline Fuel type & gasoline \\
\hline
\end{tabular}

Experimental runs were implemented in a quiet, closed space. The experimental setup is shown in Fig. 1.

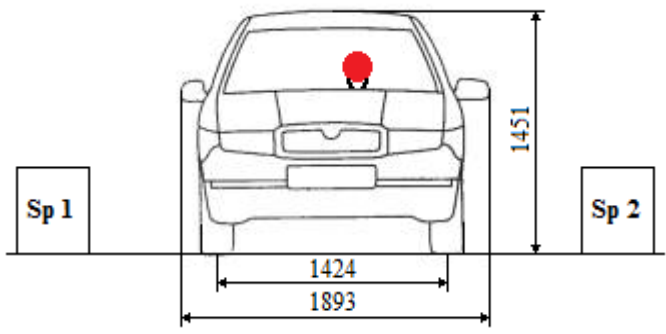

Figure 1

Experimental setup

The speakers - marked with "Sp 1" and Sp 2" - were placed on the two sides of the sample vehicle at a distance of $1 \mathrm{~m}$. In line with the recommendations for vehicle interior noise measurements of ISO 5128-1980 [34] and Putra et al. [35], the windows and doors of the sample vehicle were closed and the noise analyzer marked with red - was installed in the cabin at the driver's right ear position.

Pink noise was chosen as a measurement signal via the acoustic experiments that is a random signal that has an equal amount of noise energy in each octave [36].

Since it was previously confirmed, the noise level of the interior significantly depends on the internal environment, which is strongly influenced by the operating status [27] [31] [32] [33], multiple working conditions were examined.

The first input parameter was the sound pressure level of the cabin in case of each operating status of the sample vehicle that characterizes the internal environment. The other independent variable was the sound pressure level of the external excitation sourcing from the outer environment that is familiar with the accompanying sound phenomenon of the collision occurred. Both inputs were set at three levels. Experimental runs were developed at each possible combination of the independent variables. The levels and the belonging set values are shown in Table 2. 
Since most traffic noise prediction models deal with equivalent continuous sound pressure level [22], what is more, that parameter is strongly related to the changes of the environment [19] and to the objective evaluation of interior sound quality [26] [27] that was measured at each experimental combination.

Table 2

Levels and values of the independent variables

\begin{tabular}{|c|c|c|c|}
\hline \multirow{2}{*}{ Level } & \multicolumn{2}{|c|}{$x_{1}, \mathrm{~dB}$} & \multirow{2}{*}{$x_{2}, \mathrm{~dB}$} \\
\hline & status & noise level, dB & \\
\hline 0 & $\begin{array}{l}\text { - } \\
\text { (without operating the } \\
\text { engine and other } \\
\text { auxiliaries) }\end{array}$ & 18.4 & 71.2 \\
\hline 1 & engine at idle & 44.5 & 80.5 \\
\hline 2 & $\begin{array}{l}\text { engine at idle }+ \text { fresh } \\
\text { air fan at level II }\end{array}$ & 53.6 & 95.6 \\
\hline
\end{tabular}

\subsection{Methods of Model Construction}

In 1965, Zadeh [37] introduced the so-called fuzzy approach in order to be able to depict formerly mathematically unsolvable problems. The reason for serving more realistic results was the ability to operate uncertainty, imprecision, and vagueness. On the one hand, the fuzzy sets do not have strict limits. However, the method is mathematically precise and represents the available knowledge with really high accuracy. The aim of using the fuzzy concept is to reproduce the way of human thinking. A further advantage is that fuzzy-based systems can produce good estimations even in those cases where the available amount of data is inadequate to carry out statistical analysis. As a result, predictive models are commonly constructed with the help of that method [38] [39].

Fuzzy models consist of the following components:

Fuzzification is aimed to transform input and output values into suitable fuzzy sets. That step means the definition of the membership functions (MFs) where linguistic expressions are used. The rule base is the heart of the system, in this part is the accumulation of previously acquired expertise in the form of IF...(condition(s))...THEN...(consequence(s)) rules. The computational part of the fuzzy inference system is the inference engine. In this section, in order to define system output, the firing strength of the firing rules is determined. In those cases, when fuzzy outputs are provided, defuzzification is needed to convert those into crisp values [40].

In this paper, the results of two different types of inference engines are compared: Mamdani-type FIS and Sugeno-type one. The main difference between the methods is that in the case of the Mamdani concept, fuzzy outputs are provided, at 
Sugeno crisp or a first-order function, so no defuzzification is needed. Further features are the following [39] [40] [41] [42]:

Mamdani-type FIS:

- Output is a membership function

- Crisp results are provided by defuzzification

- $\quad$ MISO and MIMO systems

- Flexibility of system design is decreased

Sugeno-type FIS

- Output is an either crisp or first-order function

- No defuzzification is needed

- MISO systems

- System design is more flexible

Based on the fuzzy concept, a multi-input single-output fuzzy approach was applied for qualitative modeling that takes the system behavior into consideration via linguistic expressions. The results of a Mamdani- and a Sugeno-type fuzzy inference system were compared in order to estimate the equivalent continuous sound pressure level of the vehicle interior. Based on previous results [31] [32], multiple working conditions were studied. Additionally, that is the sound pressure level of the noise sourcing from the environment, which strongly influences the detectability. As a result, the input parameters are the sound pressure level of the vehicle interior belonging to the actual working condition $\left(x_{1}, \mathrm{~dB}\right)$ and the external excitation $\left(x_{2}, \mathrm{~dB}\right)$. That second one illustrates the sound phenomenon of a road accident occurred. The triangle and trapezoid-shaped membership functions of the input variables are shown in Fig. 2 for $x_{1}$ and Fig. 3 for $x_{2}$. In addition, the parameters can be found in Table 3 . The range of the independent parameters was based on normal road traffic conditions. The single-output is the estimated value of the equivalent continuous sound pressure level in the cabin $\left(L_{\text {Aeq }}, \mathrm{dB}\right)$.

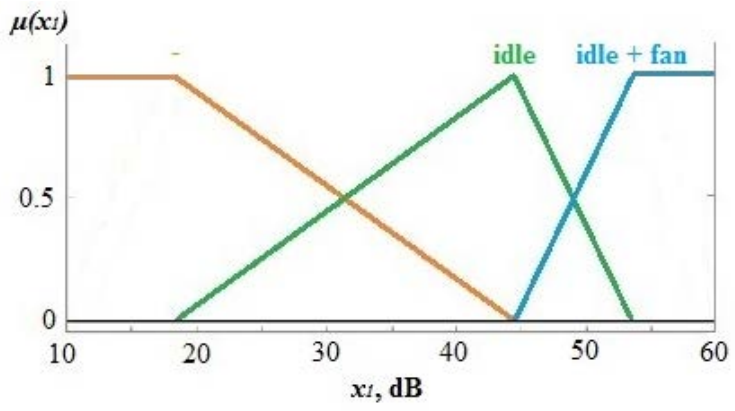

Figure 2

Membership functions of input $x_{1}$ 


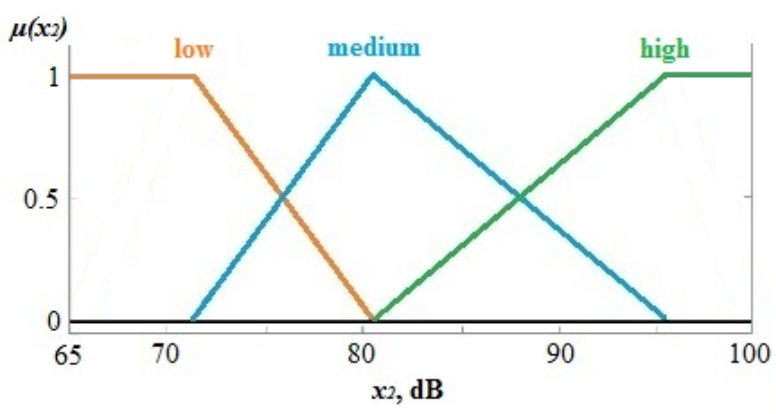

Figure 3

Membership functions of input $x_{2}$

Table 3

Parameters of input membership functions

\begin{tabular}{|c|c|c|c|}
\hline$x_{1}$ & $\mu\left(x_{1}\right)$ & $x_{2}$ & $\mu\left(x_{2}\right)$ \\
\hline- & $\{10,18.4,44.5\}$ & Low & $\{65,71.2,80.5\}$ \\
\hline engine at idle & $\{18.4,44.5,53.6\}$ & Medium & $\{71.2,80.5,95.6\}$ \\
\hline $\begin{array}{c}\text { engine at idle }+ \\
\text { FAF at level II }\end{array}$ & $\{44.5,53.6,60\}$ & High & $\{80.5,95.6,100\}$ \\
\hline
\end{tabular}

The general form of the rule base is presented in Equation (1):

$R_{i}$ : IF $x_{1}=A_{1 i 1}$ AND $x_{2}=A_{2 i 2}$ THEN $L_{\text {Aeq_calc }}=y_{i 1, i 2}$

where $R_{i}$ is the $i$ th rule $(1 \leq i \leq 9)$,

$x_{1}$ and $x_{2}$ are the input parameters,

$L_{\text {Aeq_calc }}$ is the output variable,

$A_{1 i 1}$ and $A_{2 i 2}$ are the antecedent sets,

$y_{i 1, i 2}$ is the consequent part of the $i$ th rule.

The rule base of the fuzzy interference system is shown in Table 4.

The equivalent continuous sound pressure level was chosen as single output to characterize the noise level generated in the vehicle interior. When using zeroorder Sugeno FIS, directly crisp values are resulted.

On the other hand, the dependent variables are fuzzy sets. The increased number of output membership functions provides higher accuracy and finer boundary transition. As a result, nine output MFs were defined (shown in Table 5). 
Table 4

Fuzzy rules

\begin{tabular}{|c|c|c|c|c|c|c|c|}
\hline $\begin{array}{c}\text { Rule } \\
\text { no. }\end{array}$ & \multirow{10}{*}{ IF } & $\begin{array}{l}x_{1}, \\
\text { dB }\end{array}$ & \multirow{10}{*}{ AND } & $\begin{array}{l}x_{2}, \\
\text { dB }\end{array}$ & \multirow{10}{*}{ THEN } & $\begin{array}{c}L_{\text {Aeq_Mamdani, }}, \\
\text { dB }\end{array}$ & $\begin{array}{c}L_{\text {Aeq_Sugeno, }}, \\
\text { dB }\end{array}$ \\
\hline$R_{1}$ & & Low & & - & & $y_{1}$ & 47.20 \\
\hline$R_{2}$ & & Med & & - & & $y_{2}$ & 57.45 \\
\hline$R_{3}$ & & High & & - & & $y_{3}$ & 72.75 \\
\hline$R_{4}$ & & Low & & idle & & $y_{4}$ & 49.35 \\
\hline$R_{5}$ & & Med & & idle & & $y_{5}$ & 60.20 \\
\hline$R_{6}$ & & High & & idle & & $y_{6}$ & 72.65 \\
\hline$R_{7}$ & & Low & & idle+fan & & $y_{7}$ & 55.35 \\
\hline$R 8$ & & Med & & idle+fan & & $y_{8}$ & 60.4 \\
\hline$R_{9}$ & & High & & idle+fan & & $y_{9}$ & 72.3 \\
\hline
\end{tabular}

Table 5

Parameters of the output MFs for Mamdani type fuzzy model

\begin{tabular}{|c|c|c|c|}
\hline $\boldsymbol{y}_{\boldsymbol{i}}$ & $\boldsymbol{\mu}\left(\boldsymbol{y}_{\boldsymbol{i}}\right)$ & $\boldsymbol{y}_{\boldsymbol{i}}$ & $\boldsymbol{\mu}\left(\boldsymbol{y}_{\boldsymbol{i}}\right)$ \\
\hline$y_{1}$ & $\{40,47.2,49.35\}$ & $y_{6}$ & $\{60.2,60.4,72.15\}$ \\
\hline$y_{2}$ & $\{47.2,49.35,55.35\}$ & $y_{7}$ & $\{60.4,72.15,72.65\}$ \\
\hline$y_{3}$ & $\{49.35,55.35,57.45\}$ & $y_{8}$ & $\{72.15,72.65,72.75\}$ \\
\hline$y_{4}$ & $\{55.35,57.45,60.2\}$ & $y_{9}$ & $\{72.65,72.75,80\}$ \\
\hline$y_{5}$ & $\{57.45,60.2,60.4\}$ & \multicolumn{2}{|c}{} \\
\hline
\end{tabular}

In the case of a Mamdani Fuzzy inference system, the output is a Fuzzy set. As a result, the last step is defuzzification. Since it was previously confirmed [43], for that propose the best defuzzification technique is the Largest of Maxima method. LOM gives the highest $y$ value of the maximum membership during defuzzification (see Fig. 4).

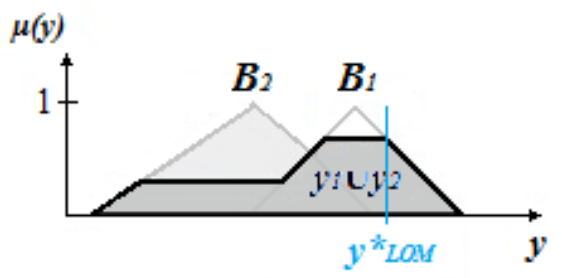

Figure 4

LOM defuzzification (based on [1]) 


\section{Investigations}

\subsection{Measurements}

Based on the levels of the input parameters, nine experimental runs were determined to contain all possible combinations. Measurements were carried out twice; the mean of the values was used to generate the above mentioned fuzzy interference system.

Since measurements were not carried out in an anechoic chamber, background noise correction was fulfilled according to Equation (2).

$$
L_{\text {Aeq }}=L_{\text {Aeq_ } m}-10 \lg \left(1-10^{-0,1\left(L_{\text {Aeq } m}-L_{\text {Aeq } b g}\right)}\right)
$$

where $L_{\text {Aeq_meas }}, \mathrm{dB}$ is the measured sound pressure level,

$L_{\text {Aeq_bg }}, \mathrm{dB}$ is the sound pressure level of the background noise [45]

\subsection{Results}

Acoustic experiments were carried out twice at each measurement point. The mean values after background noise correction $\left(L_{\text {Aeq_meas }}, \mathrm{dB}\right)$ as shown in Table 6 .

Experimental runs 1-9 were used to construct fuzzy models. To be able to choose the optimal method of Mamdani and Sugeno- type FIS, identical membership functions of the input variables $\left(x_{1}, \mathrm{~dB}\right.$, and $\left.x_{2}, \mathrm{~dB}\right)$ were set. In addition, the results provided by the models were compared to the measured values.

The differences between the measured and calculated results are called residuals. The conformity of an empirical model can be verified even by investigating the residuals. It can be stated that based on experimental data, both concepts provide an accuracy high enough for estimating the equivalent continuous sound pressure level in the interior. In case of Mamdani type inference system, the magnitude of the residuals is $-0.25 \sim 0.25 \mathrm{~dB}(-0.34 \sim 0.51 \%)$; for Sugeno the differences are between $-0.15 \sim 0.15 \mathrm{~dB}(-0.30 \sim 0.21 \%)$. However, in this sense, Sugeno was found to be a better choice.

To validate both models in the examined interval of input variables, further confirmation measurements were implemented (see rows 10-12 in Table 6).

In these cases, each analyzed working condition type was investigated; however, such values of $x_{2}$ were adjusted that were not used for generating fuzzy models. It was revealed that Mamdani type FIS provided an increased level of residuals $(-2.30 \sim 2.30 \mathrm{~dB},-3.84 \sim 3.30 \%)$ than Sugeno type one $(-0.40 \sim 0.20 \mathrm{~dB},-0.57 \sim$ $0.33 \%$ ) which held accuracy within $\pm 1 \%$. 
Table 6

Results

\begin{tabular}{|c|c|c|c|c|c|c|c|c|c|}
\hline \multirow{2}{*}{$\begin{array}{l}\text { E. } \\
\text { r. }\end{array}$} & $x_{1}$ & $x_{2}$ & $L_{\text {Aeq_meas }}$ & LAeq_Mamdani & $\Delta L_{\text {Aeq_Mamdani }}$ & $\Delta L_{\text {Aeq_Mamdani }}$ & $L_{\text {Aeq_Sugeno }}$ & $\Delta L_{\text {Aeq_Sugeno }}$ & $\Delta L_{\text {Aeq_Sugeno }}$ \\
\hline & $\mathrm{dB}$ & $\mathrm{dB}$ & $\mathrm{dB}$ & $\mathrm{dB}$ & $\mathrm{dB}$ & $\%$ & $\mathrm{~dB}$ & $\mathrm{~dB}$ & $\%$ \\
\hline 1 & 18.4 & 71.2 & 47.2 & 47.2 & 0.00 & 0.00 & 47.1 & -0.10 & $-0.21 \%$ \\
\hline 2 & 18.4 & 80.5 & 57.45 & 57.6 & 0.15 & 0.26 & 57.5 & 0.05 & $0.09 \%$ \\
\hline 3 & 18.4 & 95.6 & 72.75 & 72.8 & 0.05 & 0.07 & 72.7 & -0.10 & $-0.07 \%$ \\
\hline 4 & 44.5 & 71.2 & 49.35 & 49.6 & 0.25 & 0.51 & 49.2 & -0.15 & $-0.30 \%$ \\
\hline 5 & 44.5 & 80.5 & 60.2 & 60.0 & -0.20 & -0.33 & 60.1 & -0.10 & $-0.17 \%$ \\
\hline 6 & 44.5 & 95.6 & 72.65 & 72.4 & -0.25 & -0.34 & 72.6 & -0.05 & $-0.07 \%$ \\
\hline 7 & 53.6 & 71.2 & 55.35 & 55.2 & -0.15 & -0.27 & 55.3 & -0.05 & $-0.09 \%$ \\
\hline 8 & 53.6 & 80.5 & 60.4 & 60.4 & 0.00 & 0.00 & 60.5 & 0.10 & $0.17 \%$ \\
\hline 9 & 53.6 & 95.6 & 72.15 & 72.0 & -0.15 & -0.21 & 72.3 & 0.15 & $0.21 \%$ \\
\hline 10 & 18.4 & 83.1 & 59.9 & 57.6 & -2.30 & -3.84 & 60.1 & 0.20 & $0.33 \%$ \\
\hline 11 & 44.5 & 74.8 & 53.6 & 51.6 & -2.00 & -3.73 & 53.4 & -0.20 & $-0.37 \%$ \\
\hline 12 & 53.6 & 91.7 & 69.7 & 72.0 & 2.30 & 3.30 & 69.3 & -0.40 & $-0.57 \%$ \\
\hline
\end{tabular}

Furthermore, the fitting of the models was graphically analyzed as well. Having plotted the calculated values as a function of the measured ones, the accuracy of a model can be investigated. In the case of the perfect fit, the line fitted to the set of points is the identity function $\left(y=x\right.$, in this case, $\left.L_{\text {Aeq_calc }}=L_{\text {Aeq_meas }}\right)$.

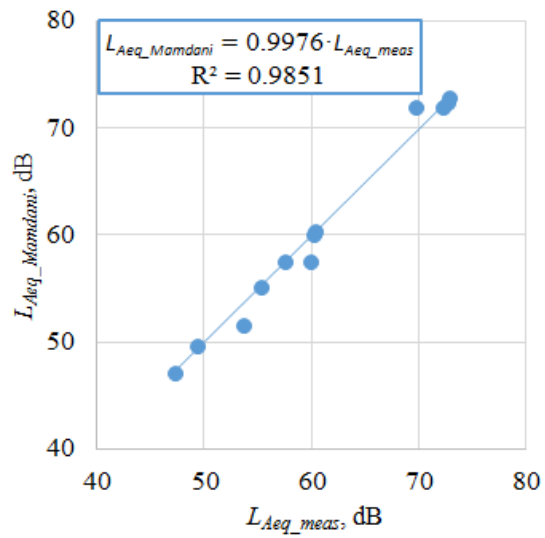

a)

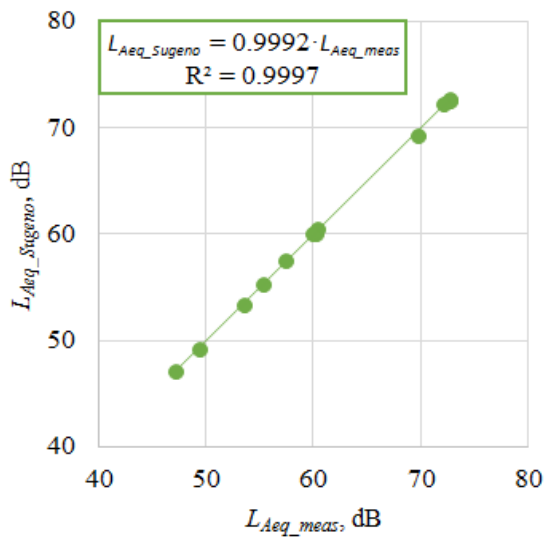

b)

Figure 5

Comparison of fuzzy models based on fitting 
Based on Fig. 5, it can be said that both models, Mamdani (Fig. 5/a) and Sugeno types (Fig. 5/b) provide a good approximation for the cabin noise level. However, the accuracy is slightly better in the case of the Sugeno type FIS model.

Additionally, the model adequacy is to examine with the distribution of the residuals. For that purpose, normality plots are used (see Fig. 6/a for Mamdani type FIS and Fig. 6/b for Sugeno type one). In this case, each 12 measurement points were evaluated together.

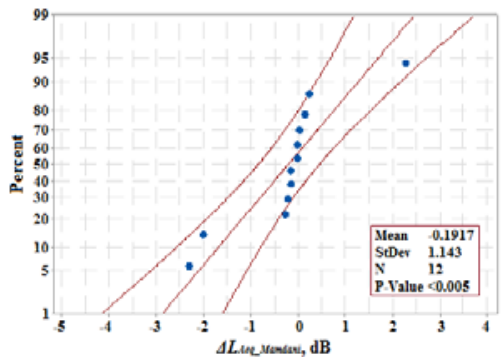

a)

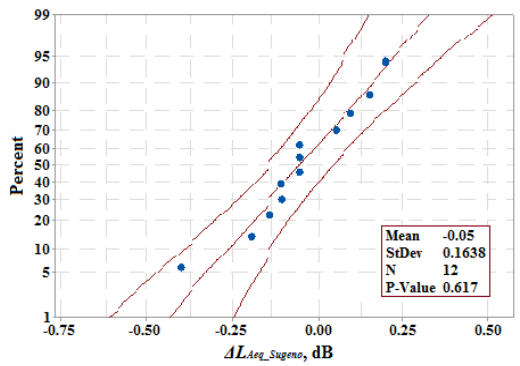

b)

Figure 6

Normality plots

In statistical sense, an empirical model is considered appropriate, if residuals follow Gaussian distribution ( $P$-Value $>0.05$ ), the value of mean is nearly zero, and the standard deviation is low. Regarding the mean, it can be revealed that both concepts provide similar results. When investigating standard deviations, it can be said that the Sugeno type model gives one order of magnitude smaller value. In addition, residuals of Mamdani type FIS do not follow a normal distribution ( $P$ Value $<0.005$ in Fig. 6/a). In contrast, in the case of Sugeno type one, $P$-Value $=$ 0.617, which represents Gaussian distribution (see Fig. 6/b).

All things considered, it can be stated that for estimating equivalent continuous sound pressure level in the vehicle interior, the Sugeno type fuzzy inference system provides higher accuracy and better conformity.

\section{Conclusions}

In this paper, an evaluation of airborne noise measurements is presented. Measurements were carried out in an enclosed space with a low level of background noise.

A SKODA FABIA COMBI (B-segment estate passenger car) was chosen as a sample vehicle. In the experiments, a Hohner Stereo 50+ double speaker system was used to generate examining sound (pink noise). The equivalent continuous sound pressure level was registered in the vehicle interior with the help of a sound analyzer that was placed in the driver's right ear position. 
In the experimental setup, the effect of two input variables was analyzed in three levels which were:

$x_{1}$, $\mathrm{dB}$ the basic noise level produced by the actual working condition of the sample vehicle and

$x_{2}, \mathrm{~dB}$ an outer sourcing additional noise, which is equivalent to the accompanying sound phenomenon of a collision.

In addition, further measurement points were determined that were used to examine for confirmation.

Experimental data registered were applied to design fuzzy-based predictive models to calculate the cabin noise level. For that propose, a Mamdani and a Sugeno type FIS were constructed. The results, the accuracy, and the conformity of the different methods were compared in the case of the experimental and confirmation measurement points.

As a result, the following conclusions can be drawn:

- Regarding experimental runs, both fuzzy models provide high accuracy, where the range of the residuals is within $\pm 1 \%(-0.34 \sim 0.51 \%$ for Mamdani and $-0.30 \sim 0.21 \%$ for Sugeno). However, in the following statements, the data used for generating and confirming the models were analyzed in total.

- Having investigated the residuals in the 12 measurement point, it was revealed that for Sugeno type FIS, the magnitude of the residuals is significantly lower: for Mamdani, that means $-2.30 \sim 2.30 \mathrm{~dB}(-3.84 \sim$ $3.30 \%)$ and $-0.40 \sim 0.20 \mathrm{~dB}(-0.57 \sim 0.33 \%)$ in case of Sugeno.

- In addition, the distribution of the residuals was studied as well. When using the Mamdani type fuzzy model, the residuals do not follow Gaussian distribution. In contrast, the ones of the Sugeno type model do with a mean of approximately zero and a low value of standard deviation.

- Furthermore, the accuracy of the methods was analyzed graphically. It can be stated that having plotted the calculated equivalent continuous sound pressure levels of the vehicle interior against the measured values, in both cases, a good approximation is provided. However, Sugeno can be considered slightly better.

- Thus, it can finally be concluded that for the unique application of interior noise prediction of passenger cars, the use of the Sugeno type fuzzy model is the better solution.

In the future, the construction of a fuzzy-based decision support system is planned, where the above-presented prediction model might provide accurate basic input parameters. The aim is to investigate the acoustic perceptibility in those cases where a lack of information occurs. 


\section{Acknowledgment}

The authors wish to thank Dániel Szabó for his help and valuable advice.

I acknowledge the financial support of this work by the Hungarian State and the European Union under the EFOP-3.6.1-16-2016-00010 project and the 20171.3.1-VKE-2017-00025 project.

\section{References}

[1] Kolnhofer-Derecskei, A., Reicher, R. Z., Szeghegyi, Á. (2019) Transport Habits and Preferences of Generations-Does it Matter, Regarding the State of The Art?. Acta Polytechnica Hungarica, 16(1), DOI: 10.12700/APH.16.1.2019.1.2

[2] Kosztolányi-Iván, G., Koren, C., Borsos, A. (2019) Can People Recognize More Than Six Road Categories?. Acta Polytechnica Hungarica, 16(6), DOI: 10.12700/APH.16.6.2019.6.13

[3] Fazekas, Z., Balázs, G., Gáspár, P. (2018) ANN-based Classification of Urban Road Environments from Traffic Sign and Crossroad Data. Acta Polytechnica Hungarica, 15(8), 83-100, DOI: 10.12700/APH.15.8.2018.8.4

[4] Orsi, C., Marchetti, P., Montomoli, C., Morandi, A. (2013) Car crashes: The effect of passenger presence and other factors on driver outcome. Safety science, 57, 35-43, DOI: 10.1016/j.ssci.2013.01.017

[5] Vollrath, M., Meilinger, T., Krüger, H. P. (2002) How the presence of passengers influences the risk of a collision with another vehicle. Accident Analysis \& Prevention, 34(5), 649-654, DOI: 10.1016/S00014575(01)00064-1

[6] Lee, C., Abdel-Aty, M. (2008) Presence of passengers: does it increase or reduce driver's crash potential?. Accident Analysis \& Prevention, 40(5), 1703-1712, DOI: 10.1016/j.aap.2008.06.006

[7] Rosenbloom, T., Perlman, A. (2016) Tendency to commit traffic violations and presence of passengers in the car. Transportation research part F: traffic psychology and behaviour, 39, 10-18, DOI: 10.1016/j.trf.2016.02.008

[8] Maasalo, I., Lehtonen, E., Summala, H. (2019) Drivers with child passengers: distracted but cautious?. Accident Analysis \& Prevention, 131, 25-32, DOI: 10.1016/j.aap.2019.06.004

[9] McEvoy, S. P., Stevenson, M. R., Woodward, M. (2007) The contribution of passengers versus mobile phone use to motor vehicle crashes resulting in hospital attendance by the driver. Accident Analysis \& Prevention, 39(6), 1170-1176

[10] Chan, M., Nyazika, S., Singhal, A. (2016) Effects of a front-seat passenger on driver attention: An electrophysiological approach. Transportation 
research part F: traffic psychology and behaviour, 43, 67-79, DOI: 10.1016/j.trf.2016.09.016

[11] Chung, E. K., Choe, B., Lee, J. E., Lee, J. I., Sohn, Y. W. (2014) Effects of an adult passenger on young adult drivers' driving speed: Roles of an adult passenger's presence and driving tips from the passenger. Accident Analysis \& Prevention, 67, 14-20, DOI: 10.1016/j.aap.2014.01.024

[12] Schmedding, K. (2011) Leichtkollisionen. Wahrnehmbarkeit und Nachweis von Pkw-Kollisionen. Vieweg+ Teubner Verlag. 2012, ISBN 978-3-83482006-8, DOI 10.1007/978-3-8348-2007-5

[13] ECE-R 42 (1980) Uniform Provisions Concerning The Approval of Vehicles with Regard to Their Front and Rear Protective Devices (Bumpers, etc.), United Nations

[14] Liu, C. H., Huang, Y. C., Chiu, C. H., Lai, Y. C., Pai, T. Y. (2016) Design and analysis of automotive bumper covers in transient loading conditions. In Key Engineering Materials (Vol. 715, pp. 174-179) Trans Tech Publications

[15] Scott, W. R., Bain, C., Manoogian, S. J., Cormier, J. M., Funk, J. R. (2010) Simulation model for low-speed bumper-to-bumper crashes. SAE International Journal of Passenger Cars-Mechanical Systems, 3(2010-010051) 21-36

[16] S. Schneider, “„Hit-and-run” - or was the impact not perceptible?”, Verkehsbund Ruhr-Rhein, 6/2005 In German: “„Unfallflucht” - oder war der Anstoß für den Fahrer nicht wahrnehmbar?”

[17] Liu, Z. S., Lu, C., Wang, Y. Y., Lee, H. P., Koh, Y. K., Lee, K. S. (2006) Prediction of noise inside tracked vehicles. Applied acoustics, 67(1), 74-91, DOI: 10.1016/j.apacoust.2005.05.003

[18] Bera, J., Pokorádi, L.: Actual Question of Measuring of the Aircraft Noise,The Challenge of Next Millennium on Hungarian Aeronautical Sciences (12 ${ }^{\text {th }}$ Hungarian Days of Aeronautical Sciences), pp. 114-123

[19] Bera, J., Pokorádi, L. (2015) Monte-Carlo Simulation of Helicopter Noise. Acta Polytechnica Hungarica, 12(2), 21-32, DOI: 10.12700/APH.12.2.2015.2.2

[20] Lindvall, J., Västfjäll, D. (2013) The effect of interior aircraft noise on pilot performance. Perceptual and motor skills, 116(2), 472-490

[21] Ivošević, J., Bucak, T., Andraši, P. (2018) Effects of interior aircraft noise on pilot performance. Applied Acoustics, 139, 8-13, DOI: 10.1016/j.apacoust.2018.04.006

[22] Singh, D., Nigam, S. P., Agrawal, V. P., Kumar, M. (2016) Vehicular traffic noise prediction using soft computing approach. Journal of 
environmental management, 183, 59-66, DOI: 10.1016/j.jenvman.2016.08.053

[23] Wang, Y. S., Lee, C. M., Kim, D. G., Xu, Y. (2007) Sound-quality prediction for nonstationary vehicle interior noise based on wavelet preprocessing neural network model. Journal of Sound and Vibration, 299(45), 933-947, DOI: 10.1016/j.jsv.2006.07.034

[24] Panza, M. A. (2015) A review of experimental techniques for NVH analysis on a commercial vehicle. Energy Procedia, 82, 1017-1023

[25] Pietila, G., Lim, T. C. (2012) Intelligent systems approaches to product sound quality evaluations-A review. Applied Acoustics, 73(10), 987-1002, DOI: 10.1016/j.apacoust.2012.04.012

[26] Chen, S., Wang, D., Wu, Y., Liu, Z., Wang, H. (2013) Objective evaluation of interior sound quality in passenger cars using artificial neural networks. SAE International Journal of Passenger Cars-Mechanical Systems, 6(201301-1704), 1078-1086, DOI: 10.4271/2013-01-1704

[27] Chen, S., Wang, D. (2014) Vehicle interior sound quality analysis by using grey relational analysis. SAE International Journal of Passenger CarsMechanical Systems, 7(2014-01-1976), 355-366, DOI: 10.4271/2014-011976

[28] Lengyel, H., Remeli, V., Szalay, Zs. (2019) Easily Deployed Stickers Could Disrupt Traffic Sign Recognition. Perner's Contacts 27 (27), 156163

[29] Lee, S. K. (2008) Objective evaluation of interior sound quality in passenger cars during acceleration. Journal of Sound and Vibration, 310(12) $149-168$

[30] Parizet, E., Nosulenko, V., Amari, M., Lorenzon, C. (2005) Free verbalizations analysis of the perception of noise and vibration in cars at idle. Acta Acustica united Acta (Suppl 1)

[31] Angelescu, A., Catalina, T., Vartires, A. (2017) Acoustic Measurements inside a Vehicle with Different Air Prototype Diffusers. Romanian Journal of Acoustics and Vibration, 14(1), 15

[32] Lukacs, J., Melegh, G. (2017) Sound Perception inside a Stationary Vehicle in Case of Frontal Audio Source. Óbuda University e-Bulletin, 7(1), 57-61

[33] Lukács, J., Melegh, G. (2019) Response surface methodology for objective evaluation of vehicle interior noise. Romanian Journal of Acoustics and Vibration, 16(1), 52-57

[34] ISO 5128-1980 (1980) Measurement of Noise inside Motor Vehicles 
[35] Putra, A., Munir, F. A., Juis, C. D. (2012) On a simple technique to measure the airborne noise in a car interior using substitution source. International Journal of Vehicle Noise and Vibration, 8(3), 275-287

[36] Kyon, D. H., Lee, W. H., Kim, M. S., Bae, M. J. (2013) Hi-pass Pink Noise: Its Acoustic Features and Standard Volume. International Journal of Multimedia and Ubiquitous Engineering, 8(6), 229-236

[37] Zadeh, L. A. (1965) Information and control. Fuzzy sets, 8(3), 338-353

[38] Tóth-Laufer, E., Horváth, R. (2017) Fuzzy model based surface roughness prediction of fine turning. FME Transactions, 45(1), 181-188

[39] Khosravanian, R., Sabah, M., Wood, D. A., Shahryari, A. (2016) Weight on drill bit prediction models: Sugeno-type and Mamdani-type fuzzy inference systems compared. Journal of Natural Gas Science and Engineering, 36, 280-297, DOI: 10.1016/j.jngse.2016.10.046

[40] Abonyi, J. (2003) Fuzzy model identification. In Fuzzy model identification for control (pp. 87-164) Birkhäuser, Boston, MA

[41] Mamdani, E. H., Assilian, S. (1975) An experiment in linguistic synthesis with a fuzzy logic controller. International journal of man-machine studies, $7(1), 1-13$

[42] Sugeno, M., Yasukawa, T. (1993) A fuzzy-logic-based approach to qualitative modeling. IEEE Transactions on fuzzy systems, 1(1), 7

[43] Lukács, J. (2019) Comparison of defuzzification methods for cabin noise prediction of passenger cars. IEEE $17^{\text {th }}$ International Symposium on Intelligent Systems and Informatics Proceedings, SISY 2019, IEEE Hungary Section, pp. 115-120

[44] Kóczy, L. T., Tikk, D. (2000) Fuzzy systems. TypoTEX, Budapest, ISBN 9639132551

[45] ECMA TR/107. (2017) An optional alternate background noise correction sensitive to the steadiness of background noise. Technical report 